\title{
Response to habitat modification by foraging Dark-chanting Goshawks Melierax metabates in a West African savanna
}

\author{
RALPH BUIJ, NIKIE VAN DORST, HENRIËTTE F. SALOMONS, \\ BARBARA M. CROES, MAURINE W. DIETZ and JAN KOMDEUR
}

\section{Summary}

Anthropogenic habitat alteration has probably contributed significantly to the decrease of raptor populations in West African savannas. To evaluate the impact of habitat degradation on foraging by sedentary Afrotropical raptors, we investigated the differences in microhabitat selection, foraging effort and energy returns between Dark-chanting Goshawks Melierax metabates inhabiting natural and transformed savannas in Cameroon. We expected that the agro-ecosystems in the transformed savannas have become unprofitable for Dark-chanting Goshawks due to scarcity of food resources. In both savanna types we radio-tracked six mated, adult males during the non-breeding season and determined foraging effort, by time spent at each perch and distance covered between perches, and energy intake through estimation of the energy value of prey items. Goshawks in natural habitats had smaller home-ranges and exploited their range more intensively than Goshawks in transformed habitats. In both natural and transformed habitats, Goshawks selected foraging patches with comparatively tall trees, underlining their importance to foraging Goshawks. The extent of shrub and herbaceous layer cover, agriculture cover, and tree density were other important predictors of foraging patch use, but their importance differed between habitats. The extent of shrub, herbaceous layer and agriculture cover were positively associated with foraging patch use in transformed habitats, suggesting that cultivated fields and ground vegetation support important prey resources for Goshawks in agro-ecosystems. The composition of broad prey categories to the diet, foraging effort and returns were comparable between habitats. However, we found indications that the proportion of heavy-bodied lizard species among reptile prey items was higher in natural than transformed habitats, whereas on average smaller lizards were more commonly caught in the latter. Mean herbaceous layer height and tree density within home ranges, both higher in natural habitat, were negatively related to prey capture rates. Tree clearance and livestock grazing thus favored greater prey capture rates in transformed habitat, offsetting a lower meal energy value compared to natural habitat. We conclude that foraging Dark-chanting Goshawks may cope with moderate land transformation, but practices focused on conservation of tall trees and ground vegetation cover would be beneficial by maintaining important prey resources and their exploitability under growing land pressure.

\section{Introduction}

Over the last 40 years unprecedented land cover and land-use changes have occurred in subSaharan Africa, driven mainly by the conversion of woodlands into croplands, shrublands, and pasture (Lambin et al. 2003, Brink and Eva 2009). Rates of land conversion have been particularly 
high in West Africa's Sudano-Sahelian savannas (Paré et al. 2008, Brink and Eva 2009, Ouedraogo et al. 2010), where some of the highest human population densities and growth rates on the continent have been reported (UN World Population Prospects 2010). The resulting habitat impoverishment, caused by loss of nest sites and prey populations that depend on vegetation cover, has been suggested to have contributed significantly to the decline of raptor populations in this region (Thiollay 2006, 2007). In light of this immense anthropogenic pressure, the situation in western Africa offers valuable insight into the ecology, ranging and behaviour of raptors confronted with such conditions, which may be representative for future conditions in many parts of the continent.

Multiple studies have examined nest site selection and diet of Afrotropical raptors in habitats modified by human activities (Machange et al. 2005, Bamford et al. 2009, Ogada and Kibuthu 2009, Virani and Harper 2009). No studies, to our knowledge, have examined foraging habitat selection at patch level scales by raptors in human-transformed landscapes. However, a thorough understanding thereof is a prerequisite to effective conservation, since maintenance of populations inside protected reserves alone may not guarantee population persistence (Chape et al. 2005, Clerici et al. 2006). Raptors concentrate foraging in habitat patches where food availability and energy returns are highest (Nishimura 1991, 1994, Ward et al. 1998), but morphological, ecological and behavioural adaptations underlie differential selection at the patch level (Thiollay and Clobert 1990). Sedentary raptors occupy year-round territories, probably heightening their sensitivity to anthropogenic land-use compared to more mobile species (Buij et al. 2013a). This may lead to their disappearance or decline from intensely exploited, overgrazed areas with little vegetation cover and impoverished prey populations (Herremans and Herremans-Tonnoeyr 2000). Cultivated fields may provide abundant prey (e.g. rodents; Buij et al. 2012), but can also lead to shifts in prey abundance and diet, with potential consequences for long-term productivity of sedentary raptors (Ogada and Kibuthu 2009).

The Dark-chanting Goshawk Melierax metabates is a medium-sized, generalist diurnal raptor that inhabits West Africa's Sudano-Sahelian savannas, where it mainly still-hunts predominantly terrestrial vertebrate prey, most often from a prominent perch such as a tree (Steyn 1982). Like other sedentary raptors (Thiollay 1978, Thiollay and Clobert 1990), the Dark-chanting Goshawk - with its high wing load, long tail and long legs - is morphologically adapted to capturing agile, often terrestrial prey in thick cover. Since human populations have appropriated an increasing proportion of scarce natural resources in agro-ecosystems, it seems likely that many areas have become unprofitable for Dark-chanting Goshawks due to scarcity of food. To examine the impact of habitat transformation on foraging in this Afrotropical raptor, we investigated differences in microhabitat selection, foraging effort and energy returns between male Dark-chanting Goshawks inhabiting natural and transformed savannas in northern Cameroon. We radio-tracked male Dark-chanting Goshawks in natural and transformed habitats, to determine foraging effort (time spent on perches and distance covered between perches) and energy returns. We examined microhabitat selection based on the premise that patch utilisation patterns reflect patch quality as in other sit-and-wait raptors (Nishimura 1991), with prey-rich patches being visited more frequently and for longer periods than other patches. We predicted that (I) apart from perch availability, the amount of herbaceous layer and shrub cover were the most important factors determining probability of foraging-patch use by foraging Dark-chanting Goshawks, given the importance of vegetation cover for small vertebrate prey populations in arid savannas (e.g. Castellano and Valone 2006); (2) foraging patches are comparatively rare (i.e. further apart and of poorer quality) in transformed compared to natural habitat, which would necessitate larger ranges, longer interperch flights and greater foraging effort in transformed habitat; and (3) differences in diet composition may result in lower energy intake in transformed compared to natural habitats, which together with lower foraging effort in the latter, will give rise to significantly greater foraging returns per effort in natural compared to transformed habitats. 


\section{Methods}

\section{Study area}

The study area $\left(10^{\circ} 40^{\prime} \mathrm{N}-11^{\circ} 24^{\prime} \mathrm{N}\right.$ and $\left.14^{\circ} 15^{\prime} \mathrm{E}-14^{\circ} 50^{\prime} \mathrm{E}\right)$ was located inside the southern half of Waza National Park and the cultivated zone south of the park in the far north of Cameroon (Fig. I). The degree of human influence on the habitat in the protected area (e.g. through livestock grazing, woodcutting; Scholte 2003) was negligible compared to the unprotected area. We therefore refer to Waza N.P. as "natural habitat" vs. "transformed habitat" for the unprotected area. The area was characterised by a Sudano-Sahelian climate, with a short rainy season (annual rainfall c.500 mm, mainly July-September), and woodland dominated by marula Sclerocarya birrea with African birch Anogeissus leiocarpus and desert date Balanites aegyptiaca, locally interspersed with dense clusters of red acacia Acacia seyal. The transformed habitat consisted of a mosaic of cultivation (10-80\% of land surface; notably dry-season sorghum but also maize, tomatoes, groundnut, onions), human settlements $(<5 \%)$, and fragments of heavily exploited woodlands $(5-35 \%)$, under severe pressure by livestock grazing and slash-and-burn activities for cultivation and wood harvesting (see also Buij et al. 2013b).

\section{Radio-tracking}

We captured 12 adult ( $>2$ years old) male Goshawks in the natural $(n=6)$ and transformed habitats $(n=6)$ between 8 November 2009 and 9 February 2010. We repeatedly drove a predefined road network of $290 \mathrm{~km}$ in transformed habitat and $80 \mathrm{~km}$ in natural habitat and considered each

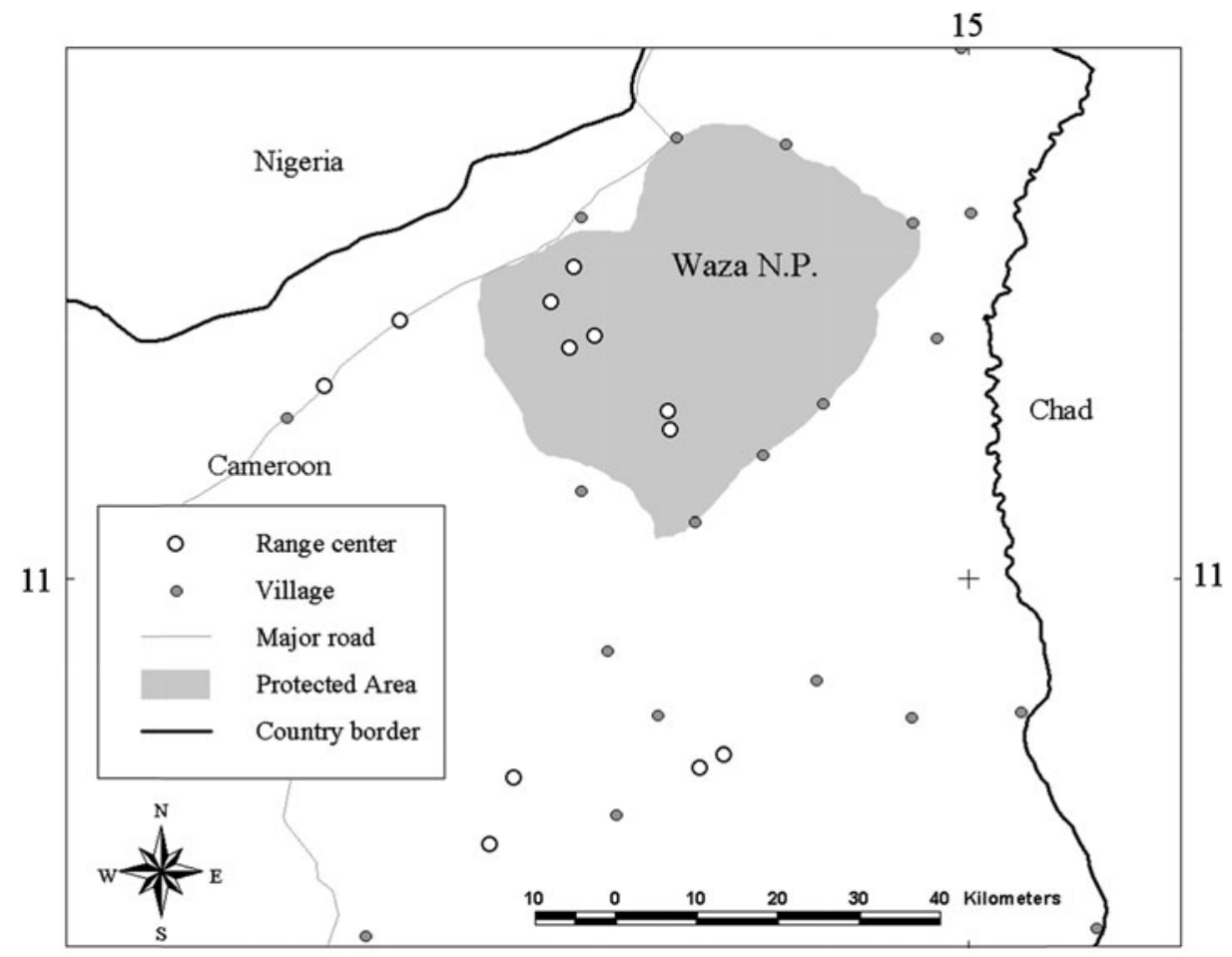

15

Figure 1. Location of territory centers of the 12 radio-tagged Dark-chanting Goshawk males in northern Cameroon. 
detected Dark-chanting Goshawk for capture, until 12 males had been caught (see Fig. I for locations of tagged males). We selected adult, mated males during the middle of the dry season (the non-breeding season), to minimise variability due to sex, age, and differences in reproductive status, and because wet-season conditions prohibited the proposed monitoring. Mated males were distinguished from unmated males by the presence of adult females in their direct vicinity $(<300 \mathrm{~m})$; the presence of a female could usually be determined within one hour of observation. Darkchanting Goshawks were trapped with a dho-gaza net or bal-chatri trap (Bloom et al. 2007), ringed, weighed to the nearest $0.1 \mathrm{~g}$ and equipped with a 10-g TW-3 single celled transmitter (Biotrack Ltd, Dorset, UK) mounted to the central tail feathers, and conforming to general safety precautions (Walls and Kenward 2007).

All twelve tagged Dark-chanting Goshawks were tracked for three consecutive days from sunrise to sunset (c.11.5-12 h) between 5 December 2009 and I March 2010, from a vehicle by three observers using a 3-element Yagi antenna and $4 \mathrm{MHz}$ Sika receiver, binoculars and a telescope. Observation conditions were ideal during each 3-day tracking session, with clear skies and no sandstorms. Observers remained inside the vehicle and the distance to the bird was kept at a minimum of $70 \mathrm{~m}$ or further if visual contact could be maintained. Monitoring was alternated between natural and transformed habitats to minimise the potentially confounding effects of changes in vegetation, climate, and prey parameters as the dry season progressed. Dark-chanting Goshawk tracking sessions were followed by vegetation surveys in the bird's range, after which the next Dark-chanting Goshawk was tracked. We compiled behaviour protocols and noted the time spent (in seconds) on each of the following five behavior categories: (I) perching: bird sitting in tree, other structures or on ground, while not engaged in feeding, (2) inter-perch flight: active flight between different perches, (3) circling: circling flight with little or no wing movement, (4) feeding: consuming prey, equivalent to meal duration for individual prey items, and (5) foraging on foot: bird walking on the ground. We also noted strikes on prey, i.e. rapid movements directed towards terrestrial, or rarely, avian prey. We distinguished three categories: I) successful strikes, when prey was captured, 2) unsuccessful strikes, when a strike at prey did not result in capture, and 3) strikes with an unknown outcome (20.5\% of 337 strikes; on average 5.7 and 5.8 strikes per bird in respectively transformed and natural habitats), i.e. strikes made at terrestrial prey but herbaceous vegetation obstructed a clear view of the bird on the ground, making it impossible to determine success and prey intake. Capture attempts classified to the latter category invariably involved small terrestrial prey (lizards, insects), which if captured was consumed on the ground, whereas large prey was always consumed above ground level. An additional 18 strikes ( $1.5 \pm 0.63$ SE strikes per bird) were classified into a fourth category: movements toward the ground that were rapidly aborted, i.e. insufficient to be classified as a strike at prey, or possibly belonged to categories 2 or 3 but could not be classified with certainty; these were excluded from calculations of strike frequency.

Incremental analysis during a pilot study based on movements of a radio-tracked male Darkchanting Goshawk indicated that $95 \%$ of the outer minimum convex polygon (MCP) range (Harris et al. 1990) was attained based on all locations after three days compared to the asymptotic MCP-estimate reached at day five. Therefore, we assumed a three-day survey would provide a reasonable representation of short-term range size. We recorded the GPS coordinates of each perch after every displacement, and the tree height and the altitude above the ground of the perch were estimated to the nearest $0.5 \mathrm{~m}$ after the Dark-chanting Goshawk had left. Relocation and identification of the perch site were fairly straightforward due to the openness of the habitat, although birds occasionally remained out of sight (e.g. when circling). Linear flight is the most energy consuming activity of raptors (Mosher 1976); thus, to assess foraging effort, the length of linear displacements was measured using the home-range extension tool in ArcView GIS 3.2 software (Esri 1999).

\section{Habitat measurements}

The vegetation structure at six patches used by foraging Dark-chanting Goshawks was compared with six nearby unused patches within the MCP range of the bird (i.e. third-order selection; 
Johnson 1980), a method successfully used to provide insight into the importance of habitat elements for foraging raptors (Kenward 1982, Beier and Drennan 1997). The foraging patch or "hunting plot" was defined as a circle, with a perch at the centre that met with the following criteria: at least one capture attempt was executed from the perch during the three-day observation period, and the cumulative time spent on the perch was longer than the time spent on other perches used for foraging. We used the average strike distance from the perch at which Darkchanting Goshawks attempted to capture prey as the radius of the hunting plot. This average strike distance ( $45 \mathrm{~m} \pm 6.0 \mathrm{SE}$; range: 7-108 $\mathrm{m}$ ) was based on 24 capture attempts by seven Darkchanting Goshawks equally divided between habitats, obtained during a pilot phase prior to the study. Strike distances were comparable in length in natural $(47.7 \mathrm{~m} \pm 9.2 \mathrm{SE}, n=12)$ and transformed habitats $(42.5 \mathrm{~m} \pm 8.0 \mathrm{SE}, n=12 ; U=67.0, P=0.77)$. For each hunting plot, we allocated a paired control plot in a fixed direction (north) of the hunting plot. To be sure that we measured an unused area, the control plot was located $>90 \mathrm{~m}$ (i.e. twice the average strike distance) from all other used perches and $>216 \mathrm{~m}$ (twice the maximum observed strike distance) from the centre of each of the five other selected hunting plots. The centre of a control plot had to meet the criteria of a potentially suitable foraging perch, i.e. a woody plant of at least $3 \mathrm{~m}$, representing the minimum perch height from which a successful strike at prey was observed.

For each of the 72 paired hunting and control plots, habitat characteristics (see Table 1 ) were sampled on the day following the three-day monitoring period. These features were hypothesised to determine prey abundance (tree density, shrub cover, herbaceous layer cover, agriculture cover) and prey accessibility (perch availability: tree height, tree density; prey accessibility: herbaceous layer cover and height) for perch-hunting Dark-chanting Goshawks, based on published information (Thiollay 1978, Thiollay and Clobert 1990). Features of the rooted herbaceous layer were measured on 4 X 4 m squares located at 4-m intervals along four $45-\mathrm{m}$ transects positioned towards the north, east, south and west and radiating out from the centre of the plot, thus covering a proportionally greater amount of habitat near the perch than further from it (following Beier and Drennan 1997). The woody plant cover was subdivided into three categories representing the woody plant strata (shrubs $<3 \mathrm{~m}$, trees: $>3 \mathrm{~m},>6 \mathrm{~m}$ ). The canopy dimensions of all shrubs in the plots were measured with a measuring pole, and the percentage cover calculated relative to the surface area of the plot. The plot was divided into four equal sections and the total surface area under cultivation estimated for each section; these areas were summed to calculate the percentage agriculture cover within the plot. All trees $>3$ and tall trees $>6 \mathrm{~m}$ inside the plot were counted to estimate their density and the height of all tall trees was measured to the nearest $0.5 \mathrm{~m}$.

Habitat characteristics were also examined at territory level to allow comparisons of vegetation composition between territories in natural and transformed habitats. To achieve this, we positioned a $1-\mathrm{km}$ transect with a fixed band width of $200 \mathrm{~m}$ along the territory's longest axis using ArcView GIS 3.2, adding a second transect perpendicular to the first if the longest axis did not attain $\mathrm{I} \mathrm{km}$.

Table 1. Vegetation parameters measured on hunting plots and paired control plots.

\begin{tabular}{ll}
\hline Vegetation parameters & Description (number of measurements per plot) \\
\hline Shrub cover $(\%)$ & Canopy cover of woody plants $<3 \mathrm{~m}(n=1)$ \\
Tree density $\left(n / \mathrm{km}^{2}\right)$ & Density of trees $>3 \mathrm{~m}(n=1)$ \\
Tall tree density $\left(n / \mathrm{km}^{2}\right)$ & Density of trees $>6 \mathrm{~m}(n=1)$ \\
Maximum tree height $(\mathrm{m})$ & Height above ground of the tallest tree $(n=1)$ \\
Agriculture cover $(\%)$ & Percentage cover of active agricultural fields \\
& (sorghum and millet; $n=1)$ \\
Herbaceous layer cover $(\%)$ & Cover of the rooted herbaceous vegetation (i.e. grasses \\
& and forbs) within twenty 4X4-m squares $(n=20)$ \\
Herbaceous layer height $(\mathrm{cm})$ & The height of the herbaceous layer for four points in \\
& each $4 \mathrm{x} 4$-m square $(n=80)^{1}$ \\
\hline
\end{tabular}

${ }^{1}$ We used a measuring pole with a $20-\mathrm{cm}$ radius circular disc dropped onto the vegetation sensu Holmes (1974). 
We determined tree density along the $1-\mathrm{km}$ transect and shrub and agriculture cover along a 200-m subsection, and herbaceous layer cover and height on sixty 4X4-m squares as described for the plots.

\section{Gross energy intake}

We found that Dark-chanting Goshawks consumed the entire prey except for one occasion (1.6\%; $n=63$ prey items) where a snake was only partially eaten. We therefore assumed that gross energy intake corresponded with the energy value of the entire prey, henceforth called "meal energy value". To enable estimation of prey body mass, we attempted to identify prey species and genus or family when identification at genus level was not possible. We estimated prey dimensions through comparison with the known length of the Dark-chanting Goshawk tarsus during feeding with the use of a telescope (Marti et al. 2007). Estimated body dimensions were snoutvent length (SVL) for lizards and snakes and body width and length, excluding tail, for small mammals. Insects were classified into three size categories: small, $<2 \mathrm{~cm}$; medium, $2-4 \mathrm{~cm}$; large: $>4 \mathrm{~cm}$. To convert body size of consumed lizards (Scincidae, Agamidae spp.) into body mass, we developed SVL-body mass regression curves using specimens collected in the study area. For mice, body mass estimates were based on known body dimensions and mass of specimens of different size and family collected in the study area (R. Buij unpubl. data). Mean body mass of grasshoppers and birds was determined from specimens collected in the field. Body mass estimates were related to meal duration (in s) via linear regressions, which can be used as a proxy measure for prey mass (Masman et al. 1986). Feeding time was strongly related to body mass estimates for small mammals $\left(F_{1,8}=38.5, \mathrm{r}^{2}=0.82, P<0.001\right)$ and lizards $\left(F_{1,29}=67.0, \mathrm{r}^{2}=0.71\right.$, $P<0.001)$, supporting the validity of our assessment.

Prey energy content, categorised to taxon and size, was determined for lizards, grasshoppers, birds, and small mammals using bomb calorimetry (kJ/g; Gessaman 1987). Representative prey specimens collected in the study area were oven dried to constant mass $( \pm 0.0001 \mathrm{~g}$ ) before homogenisation. From each prey specimen, pellets $(n=1-4)$ were prepared (c.I g) using a pellet press. The pellets were dried before weighing ( \pm 0.0001 g), and combusted in an IKA C 5000 adiabatic calorimeter, which was calibrated using a benzoic acid standard (Gessaman 1987). Energy content of prey specimens is presented in Appendix $S_{I}$ in the online supplementary material.

The energy value of snakes of different length was calculated based on body mass-length relationships of whip and grass snakes (Colubridae; Kaufman and Whitfield Gibbons 1975), which were the most commonly captured snakes, and published energy content (Secor and Nagy 1994). Dry body mass and caloric values for termites and beetles were similarly adopted from literature (Nagy et al. 1984, Williams et al. 1997, Allen 1989, Oba et al. 2008). To correct for small prey intake of strikes with unknown outcome, we determined the success rate of capture attempts involving small terrestrial prey with known outcome $(23 \% ; n=56)$, and the average energy value of the prey items involved $(22 \mathrm{~kJ})$. Henceforth, a meal energy value of $5.06 \mathrm{~kJ}(0.23 \times 22 \mathrm{~kJ})$ was ascribed to each capture attempt at terrestrial prey with uncertain outcome. Relaxing this assumption to a $50 \%$ deviation $(-/+)$ from estimated consumption did not significantly affect the outcome of comparative analyses with regard to gross energy intake. To examine foraging returns per effort, gross energy intake $(\mathrm{kJ})$ was expressed per strike, successful strike, distance covered $(\mathrm{km})$, and the total time a Dark-chanting Goshawk was observed during the three-day track session (h).

\section{Statistical analyses}

Vegetation characteristics, average gross energy intake per unit effort ( $\mathrm{km}$ traveled, h observed), and foraging data were averaged per individual range and compared with independent samples t-tests or Mann-Whitney U-tests. Standard univariate linear and quadratic regression models were used to investigate the relationships between range size and tree density, tree height, shrub cover, and herbaceous cover and height at range-level, considering the entire dataset $(n=12$ Dark-chanting Goshawks). To test which habitat features at range-level were related to foraging 
success, we used linear and quadratic regression models with the mean number of successful strikes per hour as dependent variable and tree density and height, herbaceous layer cover and height within ranges as independent variables.

Dark-chanting Goshawk foraging data were analysed using Generalized Linear Mixed Models (GLMMs) implemented in R (version 2.6.1., function lmer in R package lme4). To test our assumption that hunting plots were indeed sites where the expected returns were greatest, we examined whether time spent on perches was positively related to hunting attempts made from those perches, taking into account inter-individual variation. Hereto, we used GLMMs with a negative binomial distribution and log link function, with time spent on perches as dependent variable, bird ID as random variable, and hunting attempt (yes $=1$, no $=0$ ) as categorical explanatory variable.

To examine which habitat variables best explained the probability of hunting patch use by Dark-chanting Goshawks, we constructed mixed effects logistic regression models with probability of use ( $\mathrm{o}=$ paired control plot [reference], $\mathrm{I}=$ hunting plot $)$ as the dependent variable. Based on published information, we explored the following predictor variables: 1 ) percentage cover of shrubs, which provide refuges for small terrestrial vertebrates (lizards, rodents; Díaz 1992, Blaum et al. 2007); 2) tree density, or tall tree density, based on positive relationships between arboreal lizard abundance and tree density and size (Cooper and Whiting 2000, Meik et al. 2002); 3) herbaceous layer cover and height (averaged across plots), because ground cover is positively associated with abundance of terrestrial lizards and small mammals in arid savannas (Castellano and Valone 2006, Buij et al. 2013c); 4) the percentage cover of cultivated fields, with often abundant rodent prey (Buij et al. 2012); and 5) maximum tree height, because tree height is an important determinant of prey accessibility for perch-hunting raptors in savannas (Thiollay and Clobert 1990). We fitted models using all possible combinations of main effects and included interaction terms between tree height and herbaceous layer cover (respecting the marginality principle for modeling; Nelder 1977), because we expected that Dark-chanting Goshawks adapted perch height in response to differences in herbaceous layer cover (cf. Thiollay and Clobert 1990), affecting their patch use. Bird ID was included as random variable in the above-mentioned models to account for inter-individual variation. Before modelling, we verified collinearity between predictor variables $(r>0.7)$ using Spearman rank correlation tests and retained only those variables that had the lowest corrected Akaike information criterion $\left(\mathrm{AIC}_{\mathrm{c}}\right)$ value from univariate models of the two predictors (Burnham and Anderson 2002); this meant that tall tree density and herbaceous layer height were excluded from models. We calculated $\mathrm{AIC}_{\mathrm{c}}$ to obtain the model that best fit the data and considered the following levels of empirical support for models: $\triangle \mathrm{AIC}_{\mathrm{c}}<2$ substantial support, $\Delta \mathrm{AIC}_{\mathrm{c}}>4$ considerably less support (Burnham and Anderson 2002). We used the dredge function in $\mathrm{R}$ (part of $\mathrm{R}$ package MuMIn, version 1.9.5; Barton 2009) to estimate the relative importance of each predictor based on the Akaike weights $\left(w_{\mathrm{i}}\right)$.

Differences in time budgets between habitats were examined using GLMMs with negative binomial distribution and log link function with the time spent on perching, inter-perch flight, circling, and foraging on foot as dependent variables. Time spent was defined here as the time period spent on a particular behaviour until the bird switched to another behaviour. We constructed a second set of models with the relative contribution of each behavioural category to total observation time, i.e. the percentage time spent per day on each behavioral category, as dependent variables. Habitat (natural/transformed) was included as categorical predictor variable in these models and bird ID as random variable. To test for differences in the length of individual linear displacements between habitats, GLMMs with negative binomial distribution and log link were used with bird ID as random variable, the length of displacements as dependent variable, and habitat type as explanatory variable. For differences between habitats in minimum inter-perch distance, i.e. the distance of each structure (tree, electricity pole) used as a perch to the nearest neighbouring structure used as a perch at any time during the three-day track period, GLMMs with normal distribution and identity link function were used, with bird ID as a random variable, the log transformed inter-perch distances as dependent variable, and habitat type as the categorical explanatory variable. 
To test for associations between prey choice and habitat type, we used GLMMs with a multinomial distribution and log link function to examine associations between habitat (natural/transformed) and three prey categories (reptiles, rodents, and infrequent - and therefore lumped - "other prey" such as birds and insects). Prey type was included as dependent variable, habitat as categorical fixed effect, and bird ID was added as a categorical random variable to account for inter-individual differences in prey choice. To test for differences in gross energy return (rounded to kJ) per successful strike between habitats, we used GLMMs with negative binomial distribution and log link function with meal energy value as dependent variable, bird ID as a random variable, and habitat type as categorical explanatory variable. We used the same approach to test for differences in gross energy return per strike. All means are given \pm SE.

\section{Results}

\section{Habitat features of Dark-chanting Goshawk ranges}

Mean range size was greater in transformed compared to natural habitat (Table 2). Comparisons of vegetation structural characteristics between habitat types at the territory level indicated on average higher overall tree densities and higher tall-tree densities in natural than transformed habitat (Table 3). Territories in natural habitats also had a higher herbaceous layer cover, but a lower shrub cover than in the transformed habitat. Maximum tree height tended to be greater in natural habitats. The proportion of herbaceous layer cover was comparable between habitats. MCP-range size was not significantly related to any measure of vegetation structure at the territory-size scale, also when relationships were considered separately for each habitat type. However, range size tended to decline with increasing tree density inside ranges $\left(F_{1,10}=3.56\right.$, $\left.\mathrm{r}^{2}=0.26, P<0.10\right)$.

\section{Comparison of hunting plots and paired control plots}

Dark-chanting Goshawks spent more time at perches from which capture attempts were observed $(41.7 \pm 3.93 \mathrm{~min})$ than at perches from which no attempts were observed (12.5 $\pm 1.03 \mathrm{~min}$; $\left.F_{1,869}=162.4, P<0.001\right)$, confirming our assumption that they spent more time in patches that had larger potential returns than in patches with lower potential returns. Table 4 summarizes the results of generalized mixed models of the probability of use of foraging patches by Goshawks,

Table 2. Foraging statistics (mean $\pm \mathrm{SE}$ ) for 12 male Dark-chanting Goshawks in natural and transformed habitats between December 2009 and March 2010. Asterisks indicate significant differences between habitats with independent samples t-test; ${ }^{*} P<0.05$.

\begin{tabular}{llccc}
\hline Foraging statistics & $\begin{array}{l}\text { Natural habitat } \\
(n=6)\end{array}$ & Range & $\begin{array}{l}\text { Transformed } \\
\text { habitat }(n=6)\end{array}$ & Range \\
\hline MCP-range size $\left(\mathrm{km}^{2}\right)^{*}$ & $1.14 \pm 0.17$ & $0.57-1.87$ & $1.88 \pm 0.18$ & $1.35-2.52$ \\
Perches used $(n)$ & $70.2 \pm 10.2$ & $62-116$ & $64.3 \pm 7.4$ & $46-91$ \\
Time observed $(\mathrm{h})$ & $27.2 \pm 2.0$ & $19.4-32.4$ & $31.9 \pm 0.9$ & $29.6-34 \cdot 5$ \\
Body mass $(\mathrm{g})$ & $552 \pm 5.2$ & $534-566$ & $552 \pm 10.3$ & $518-586$ \\
Body mass/wing length & $17.9 \pm 0.22$ & $17 \cdot 3-18.6$ & $18.1 \pm 0.36$ & $17.2-19.5$ \\
Number of strikes $/ \mathrm{h}^{1}$ & $0.86 \pm 0.19$ & $0.25-1.55$ & $1.01 \pm 0.09$ & $0.74-1.36$ \\
Number of successful strikes/h* & $0.12 \pm 0.03$ & $0.07-0.19$ & $0.23 \pm 0.03$ & $0.14-0.37$ \\
Distance covered $(\mathrm{km}) / \mathrm{h}$ & $1.25 \pm 0.15$ & $0.59-2.00$ & $0.97 \pm 0.13$ & $0.68-1.59$ \\
Energy return $(\mathrm{kJ}) / \mathrm{km}$ & $18.8 \pm 2.62$ & $8.51-29.6$ & $20.5 \pm 3.01$ & $13 \cdot 3-33.6$ \\
Energy return $(\mathrm{kJ}) / \mathrm{h}$ & $19.9 \pm 1.81$ & $13.1-27.4$ & $19.0 \pm 2.23$ & $10.7-24.3$ \\
\hline
\end{tabular}

${ }^{1}$ Includes successful strikes $\left(n_{\text {natural }}=20, n_{\text {transformed }}=43\right)$, unsuccessful strikes $\left(n_{\text {natural }}=87, n_{\text {transformed }}=118\right)$, and strikes with unknown outcome $\left(n_{\text {natural }}=35, n_{\text {transformed }}=34\right)$. 
Table 3. Vegetation features (mean $\pm \mathrm{SE}$ ) for territories of 12 male Dark-chanting Goshawks in natural and transformed habitats in northern Cameroon, December 2009-February 2010. Vegetation parameters were recorded along a $1-\mathrm{km}$ transect with a fixed band width of $200 \mathrm{~m}$ centered on the territory. Asterisks indicate significant differences between habitats with independent samples t-test or Mann-Whitney U-tests; ${ }^{* * *} P<0.01$, ${ }^{* *} P<0.05,{ }^{*} P<0.10$.

\begin{tabular}{lcccc}
\hline Range characteristics & $\begin{array}{l}\text { Natural habitat } \\
(n=6)\end{array}$ & Range & $\begin{array}{l}\text { Transformed } \\
\text { habitat }(n=6)\end{array}$ & Range \\
\hline Shrub cover $(\%)^{* * *}$ & $1.27 \pm 0.15$ & $0.71-1.73$ & $3.96 \pm 0.44$ & $2.52-5.82$ \\
Tree density $\left(n / \mathrm{km}^{2}\right)^{* *}$ & $1189 \pm 311$ & $207-2390$ & $467 \pm 200$ & $63-1160$ \\
Tall tree density $\left(n / \mathrm{km}^{2}\right)^{* *}$ & $880 \pm 207$ & $123-1605$ & $282 \pm 130$ & $23-800$ \\
Maximum tree height $(\mathrm{m})^{*}$ & $19.8 \pm 1.56$ & $14-23$ & $15.3 \pm 0.49$ & $14-17$ \\
Agriculture cover $(\%)$ & - & - & $38.9 \pm 9.40$ & $14.6-74.8$ \\
Herbaceous layer cover $(\%)$ & $8.55 \pm 1.96$ & $3.25-16$ & $6.56 \pm 2.52$ & $3.20-19$ \\
Herbaceous layer height $(\mathrm{cm})^{* * *}$ & $12.4 \pm 1.83$ & $10-21.4$ & $4.22 \pm 0.97$ & $2.34-8.13$ \\
\hline
\end{tabular}

based on the habitat predictors. All top models with comparable support $\left(\Delta \mathrm{AIC}_{\mathrm{c}}<2\right)$ in both transformed and natural habitats included a maximum tree height effect on foraging patch use. Inspection of the parameter estimates for the best-supported models suggested that the probability of use of foraging patches by Dark-chanting Goshawks increased with maximum tree height in natural $(\beta=0.241 \pm 0.068)$ and transformed habitats $(\beta=0.235 \pm 0.078)$.

Among models of high to moderate importance in transformed habitat $\left(\Delta \mathrm{AIC}_{\mathrm{c}}<4\right)$, those that included a maximum tree height effect on patch use comprised $97 \%$ of the total model weight. Herbaceous layer cover was another important predictor, included in 15 models within $\Delta \mathrm{AIC}_{\mathrm{c}}<4$ that together comprised $67 \%$ of total model weight. Models with shrub cover and agriculture cover each contributed $51 \%$ to the total model weight for $\Delta \mathrm{AIC}_{\mathrm{c}}<4$ models, those with an interaction between herbaceous layer cover and tree height $25 \%$, and those with tree density $22 \%$. The top models $(\triangle \mathrm{AICc}<2$; Table 4$)$ provided support for positive relationships between foraging patch use and agriculture cover, shrub cover, and herbaceous layer cover, this suggests that Dark-chanting Goshawks concentrated their foraging effort in patches where agriculture and ground vegetation cover were comparatively high. Three of these best-supported models also included an interaction effect between herbaceous layer cover and tree height, but there was little evidence that this affected patch use.

In natural habitat, models with a tree height effect comprised $82 \%$ of the total model weight for models of $\Delta \mathrm{AIC}_{\mathrm{c}}<4$. Models with shrub cover and tree density contributed $20 \%$ and $19 \%$ respectively to total model weight, and those with herbaceous layer cover $13 \%$. These results suggest that habitat covariates differed in their importance between habitat types: in particular, herbaceous layer cover was a relatively more important predictor of foraging patch use in transformed than in natural habitats. The top models $\left(\Delta \mathrm{AIC} \mathrm{C}_{\mathrm{c}}<2\right.$; Table 4$)$ suggested that foraging patch use differed with shrub cover inside patches, similar to transformed habitat, and with tree density; but evidence that these covariates affected patch use was weak.

\section{Movements and foraging effort}

Despite larger ranges in transformed habitat, the length of single linear displacements did not differ between natural $(277 \pm 9.06 \mathrm{~m})$ and transformed habitats $\left(287 \pm 11.3 \mathrm{~m} ; F_{1,1337}=0.17\right.$, $P=$ o.68). Relative and absolute time spent on perching, inter-perch flight, circling, and foraging on foot did not differ between habitats. Similarly, foraging efforts, i.e. the distance covered per hour and the number of strikes at prey per hour, did not differ between habitats (Table 2). There was also no difference in the number of perches used between territories in natural and transformed habitat (Table 2). But the minimum inter-perch distance, i.e. the distance of each perch to the nearest neighboring perch, was greater in transformed $(89.9 \pm 3.17 \mathrm{~m})$ than natural habitat 
Table 4. Mixed effects logistic regression models comparing probability of foraging patch-use with habitat features within territories of six male Dark-chanting Goshawks in natural and transformed habitats ( $n=36$ hunting plots vs. $n=36$ paired control plots in each habitat type). All possible models with main effects were fitted: herbaceous layer cover (herb), shrub cover (shrub), agriculture cover (agri), tree density (treedens), and maximum tree height (treeheight), and the interaction of tree height with herbaceous layer cover. Bird ID (1-12) was added as a random effect. Only parameter estimates for models with $\Delta \mathrm{AIC}_{\mathrm{c}}<4$ from the best model are shown, in order of increasing $\Delta \mathrm{AIC}_{\mathrm{c}}$, with models $\Delta \mathrm{AIC}_{\mathrm{c}}<2$ having substantial support (Burnham and Anderson 2002). Superscripts with estimates of intercept and effect size indicate significance levels: $P<0.10\left(^{+}\right) ; P<0.05\left(^{*}\right) ; P<0.01\left(^{* *}\right)$; and $P<0.001\left(^{* *}\right)$. The Akaike weight $w_{\text {i, }}$, i.e. the weight of evidence in support of the model, was calculated relative to all models.

\begin{tabular}{|c|c|c|c|c|c|c|c|c|c|c|c|}
\hline \multicolumn{12}{|c|}{ Natural habitat } \\
\hline Intercept & $\beta$ treeheight & Bagri & $\beta$ shrub & $\beta$ herb & $\beta$ treedens & $\beta$ treeheight:herb & $\mathrm{df}$ & $\log \operatorname{Lik}$ & $\mathrm{AIC} c$ & $\triangle \mathrm{AIC} c$ & $w_{\mathrm{i}}$ \\
\hline$-3.255^{* * *}$ & $0.241^{* * *}$ & - & - & - & - & - & 3 & -41.655 & 89.7 & 0.00 & 0.353 \\
\hline$-3.415^{* * *}$ & $0.237^{* * *}$ & - & 0.176 & - & - & - & 4 & -41.433 & 91.5 & 1.80 & 0.144 \\
\hline$-3.089^{* *}$ & $0.239^{* * *}$ & - & - & - & $-2,77 \mathrm{e}-05$ & - & 4 & -41.506 & 91.6 & 1.95 & 0.134 \\
\hline$-3.273^{* * *}$ & $0.235^{* * *}$ & - & - & 0.012 & - & - & 4 & -41.572 & 91.7 & 2.08 & 0.125 \\
\hline$-3.229^{* *}$ & $0.232^{* * *}$ & - & 0.227 & - & $-3,96 e-05$ & - & 5 & -41.167 & 93.2 & 3.58 & 0.059 \\
\hline \multicolumn{12}{|c|}{ Transformed habitat } \\
\hline Intercept & $\beta$ treeheight & Bagri & $\beta$ shrub & $\beta$ herb & $\beta$ treedens & $\beta$ treeheight:herb & $\mathrm{df}$ & logLik & $\mathrm{AICc}$ & $\triangle \mathrm{AIC}_{\mathrm{C}}$ & $w_{\mathrm{i}}$ \\
\hline$-3.941^{* * *}$ & $0.235^{* *}$ & $0.013^{+}$ & $0.220^{+}$ & 0.081 & - & - & 6 & -38.736 & 90.8 & 0.00 & 0.108 \\
\hline$-2.58 I^{* * *}$ & $0.242^{* * *}$ & - & - & 0.068 & - & - & 4 & -41.411 & 91.4 & 0.65 & 0.078 \\
\hline$-2.484^{* * *}$ & $0.210^{* *}$ & - & 0.159 & - & - & - & 4 & -41.512 & 91.6 & 0.86 & 0.070 \\
\hline$-3.185^{* * *}$ & $0.218^{* *}$ & 0.010 & $0.221^{+}$ & - & - & - & 5 & -40.412 & 91.7 & 0.97 & 0.067 \\
\hline$-2.677^{* *}$ & 0.136 & $0.012^{+}$ & - & -0.080 & - & 0.031 & 6 & -39.222 & 91.7 & 0.97 & 0.067 \\
\hline$-3.271^{* * *}$ & $0.266^{* * *}$ & 0.010 & - & $0.088^{+}$ & - & - & 5 & -40.431 & 91.8 & 1.01 & 0.065 \\
\hline$-2.879^{* * *}$ & $0.218^{* *}$ & - & 0.146 & 0.059 & - & - & 5 & -40.443 & 91.8 & 1.03 & 0.065 \\
\hline$-2.077^{* *}$ & $0.232^{* * *}$ & - & - & - & - & - & 3 & -42.731 & 91.8 & 1.05 & 0.064 \\
\hline$-3 \cdot 441^{* *}$ & 0.150 & $0.015^{+}$ & 0.193 & -0.036 & - & 0.022 & 7 & -38.168 & 92.1 & 1.32 & 0.056 \\
\hline$-1.995^{*}$ & 0.147 & - & - & -0.050 & - & 0.020 & 5 & -40.710 & 92.3 & 1.56 & 0.049 \\
\hline$-2.408^{* *}$ & $0.244^{* * *}$ & 0.006 & - & - & - & - & 4 & -42.294 & 93.2 & 2.42 & 0.032 \\
\hline$-3.935^{* * *}$ & $0.233^{* *}$ & $0.013^{+}$ & 0.214 & 0.081 & 1,6oe-05 & - & 7 & -38.732 & 93.2 & 2.45 & 0.032 \\
\hline$-2.426^{*}$ & 0.158 & - & 0.130 & -0.017 & - & 0.013 & 6 & -40.105 & 93.5 & 2.74 & 0.028 \\
\hline$-3 \cdot 371^{* * *}$ & $0.245^{* *}$ & 0.011 & - & $0.088^{+}$ & 1,18e-04 & - & 6 & -40.129 & 93.5 & 2.78 & 0.027 \\
\hline
\end{tabular}


Table 4. Continued.

\begin{tabular}{|c|c|c|c|c|c|c|c|c|c|c|c|}
\hline \multicolumn{12}{|c|}{ Transformed habitat } \\
\hline Intercept & $\beta$ treeheight & Bagri & $\beta$ shrub & $\beta$ herb & $\beta$ treedens & $\beta$ treeheight:herb & $\mathrm{df}$ & $\log L i k$ & $\mathrm{AIC} c$ & $\triangle \mathrm{AIC}_{\mathrm{C}}$ & $w_{\mathrm{i}}$ \\
\hline$-2.574^{* * *}$ & $0.233^{* *}$ & - & - & 0.067 & $4,23 \mathrm{e}-05$ & - & 5 & -41.360 & 93.6 & 2.86 & 0.026 \\
\hline$-2.539^{* *}$ & $0.217^{* *}$ & - & 0.183 & - & $-5,24 \mathrm{e}-05$ & - & 5 & -41.448 & 93.8 & 3.04 & 0.024 \\
\hline$-2.088^{* *}$ & $0.223^{* *}$ & - & - & - & $4,81 \mathrm{e}-05$ & - & 4 & -42.660 & 93.9 & 3.15 & 0.022 \\
\hline$-2.774^{* *}$ & 0.133 & $0.013^{+}$ & - & -0.068 & $7,29 \mathrm{e}-05$ & 0.029 & 7 & -39.135 & 94.0 & 3.25 & 0.021 \\
\hline$-2.936^{* * *}$ & $0.226^{* *}$ & - & 0.168 & 0.060 & $-4,92 \mathrm{e}-05$ & - & 6 & -40.390 & 94.1 & $3 \cdot 31$ & 0.021 \\
\hline$-3.189^{* * *}$ & $0.219^{* *}$ & 0.010 & 0.224 & - & $-8,22 e-06$ & - & 6 & -40.411 & 94.1 & $3 \cdot 35$ & 0.020 \\
\hline$-3.439^{* *}$ & 0.151 & $0.014^{+}$ & 0.198 & -0.037 & -1,61e-05 & 0.022 & 8 & -38.164 & 94.6 & 3.85 & 0.016 \\
\hline$-1.994^{*}$ & 0.147 & - & - & -0.050 & $-2,04 \mathrm{e}-06$ & 0.021 & 6 & -40.710 & 94.7 & 3.95 & 0.015 \\
\hline
\end{tabular}


$\left(63.5 \pm 2.08 \mathrm{~m} ; F_{1,805}=17.5, P<0.001\right)$. The 1.4 times greater inter-perch distance in transformed habitat compared to natural habitat and the comparable strike distances in both habitats, suggests that Dark-chanting Goshawks in the natural habitat more often searched overlapping areas, i.e. they exploited their range more intensively than those in the transformed habitat.

\section{Diet and gross energy intake}

Body mass of Dark-chanting Goshawks did not differ between habitats and the same was true for a proxy measure of wing load (body mass/wing length; Table 2), suggesting that body condition and energy requirements of flight did not differ between individuals in natural and transformed habitats. We found no association between habitat type and the contribution of reptiles ( $70 \%$ of identified prey items recorded; $n=63)$, rodents $(19 \%)$, and other prey (11\%; birds and insects; $F_{2,59}=0.46, P=0.63$ ) to the diet (Fig. 2). Despite the absence of dietary differences in terms of broad prey categories, the proportion of Agamidae spp. among reptile prey items identified to family level was higher in natural $(33.3 \% ; n=12)$ than transformed habitat $(9.4 \% ; n=32)$; whereas on average smaller lizards (Scincidae, Lacertidae, Gekkonidae spp.) were more commonly caught in transformed (71.9\%) than natural habitat (41.7\%). No such difference was noted for rodents (Muridae spp.). The gross energy return measured by effort or time did not differ between natural and transformed habitats (Table 2). Gross energy return per strike (successful and unsuccessful strikes combined) was also comparable between natural $(32.8 \pm 7.67 \mathrm{~kJ} / \mathrm{strike})$ and transformed habitats $\left(26.1 \pm 4.34 \mathrm{~kJ} / \mathrm{strike} ; F_{1,266}=1.19\right.$, $P=0.28)$. Dark-chanting Goshawks in natural and transformed habitat did differ by a higher frequency of successful strikes in the latter (Table 2). On the other hand, gross energy return per successful strike was higher in natural $(153.2 \pm 25.9 \mathrm{~kJ} / \mathrm{strike})$ than transformed habitat $\left(79.2 \pm 10.9 \mathrm{~kJ} /\right.$ strike; $\left.F_{1,61}=7.06, P<0.05\right)$, as a result of a higher meal energy value (especially of reptiles) in natural compared to transformed habitats (Fig. 3). The frequency of successful strikes declined with herbaceous layer height and tree density within ranges (Table 5), but was unrelated to herbaceous layer cover.

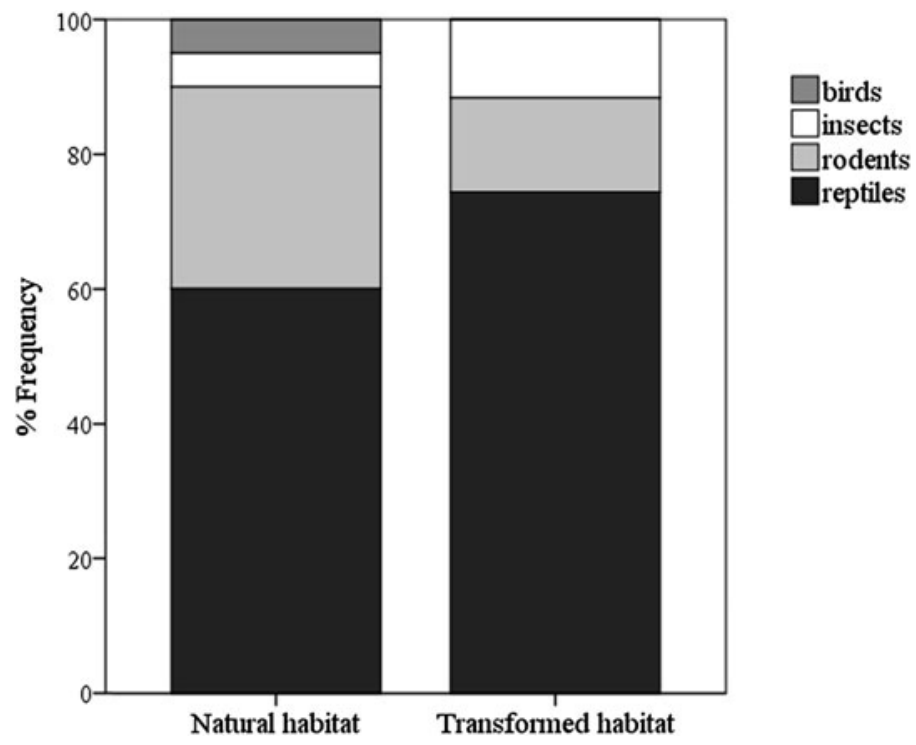

Figure 2. Percentage contribution of the broad prey categories to the diets of six Goshawks in natural ( $n=20$ prey items) and six Goshawks in transformed habitats ( $n=43$ items). 


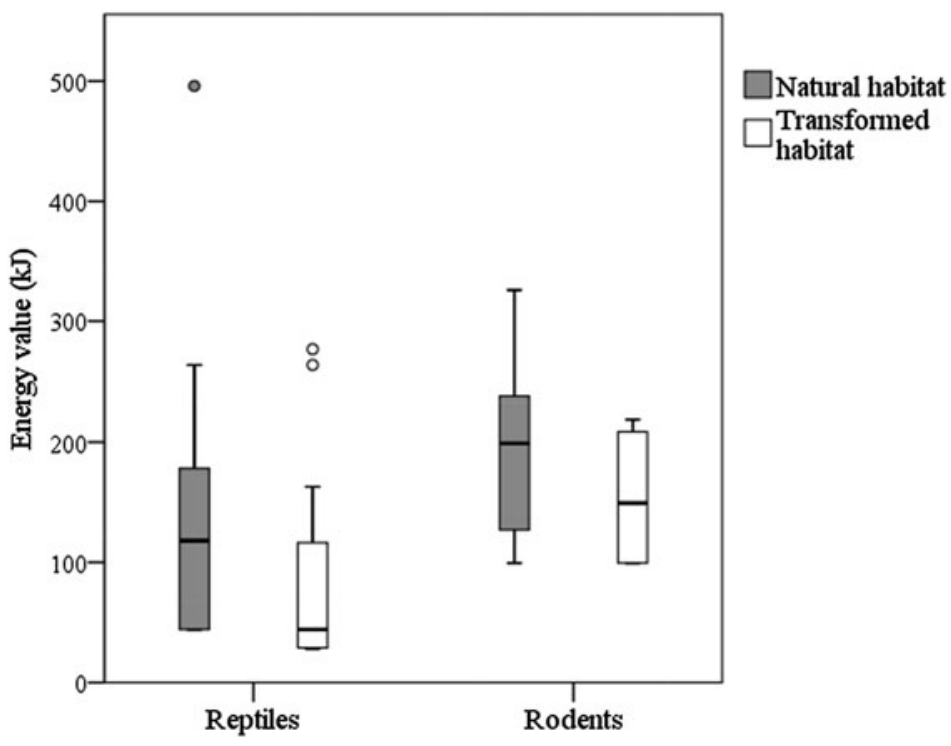

Figure 3. Box plots showing the distribution of energy values of reptile $(n=44)$ and rodent prey items $(n=12)$, for natural and transformed habitat. Medians are denoted by solid black lines while the top and bottom box edges denote the first and third quartile, whiskers denote the largest and smallest data, and outliers as separate points. Prey energy value differed significantly between habitats for reptiles $\left(\mathrm{U}_{12,32}, \mathrm{z}=-2.48, P<0.05\right)$, but not for rodents $\left(\mathrm{t}_{10}=-1.07, P=0.31\right)$.

\section{Discussion}

Contrary to expectations, we did not detect a significant shift in the contribution of broad prey categories to the diet of Dark-chanting Goshawks in response to anthropogenic modification of their savanna habitat. Dark-chanting Goshawks in the human-transformed habitat neither adjusted their activity patterns, nor did they invest more energy in foraging. Rather, in transformed habitat higher prey capture rates compensated for the less profitable prey items (prey items with a lower energy value). Dark-chanting Goshawks in natural habitat were limited in their strike success rate by a relatively thick herbaceous layer and high tree density. Thus, anthropogenic land-use appeared to improve prey accessibility for Dark-chanting Goshawks, through tree clearance and a reduction of grass height resulting from livestock grazing, but reduced the quality of individual prey items. Although prey size has been found to vary with land-use in other raptors (Rodríguez et al. 2006, Cardador et al. 2012), to our knowledge this is the first study that demonstrates a deterioration of prey quality with land transformation in an African raptor. These results seem indicative of constraints on body mass of small vertebrates in transformed

Table 5. Relationship between mean strike success rate (number successful strikes/hour) by Dark-chanting Goshawks $(n=12)$ and tree density and herbaceous layer height within ranges.

\begin{tabular}{|c|c|c|c|}
\hline Explanatory variables & $\beta$ & $t$ & $P$ \\
\hline Tree density & $-7.508 \mathrm{E}-5 \pm 0.000$ & -4.051 & $<0.01$ \\
\hline Herbaceous layer height & $-0.006 \pm 0.002$ & -2.615 & $<0.05$ \\
\hline $\begin{array}{l}\text { Constant } \\
\text { ANOVA: } F_{2,9}=16.2, \\
\quad r^{2}=0.78, P<0.01\end{array}$ & $0.29 \pm 0.025$ & 11.682 & $<0.001$ \\
\hline
\end{tabular}


habitat, assuming that Dark-chanting Goshawks will attempt to maximise their foraging returns by focusing on the most profitable prey available to them (Stephens and Krebs 1986). Such differences in body mass may have been imposed by various aspects of land use; for example, terrestrial vertebrates such as lizards were found to be more active where grazing pressure is high (Wasiolka et al. 2009), which may negatively impact their condition and body mass (Amo et al. 2007). In addition, prey species composition or accessibility may change following human exploitation leading to structural vegetation changes of savannas (Meik et al. 2002), and larger, more profitable prey species might be more commonly encountered in natural habitat. Indeed, we found indications that Dark-chanting Goshawks captured proportionally more Agamid lizards, which are relatively heavy-bodied, in natural habitat than in transformed habitat, implying that high-quality, larger reptile species may be more readily available in natural habitats.

Forage-patch use by Dark-chanting Goshawks in natural and transformed habitats was strongly and positively influenced by the presence of tall trees, which provide cover and perches from which to hunt. In addition, we found evidence that tree density, herbaceous layer, shrub, and agriculture cover influenced patch use, although the importance of these covariates differed between habitats. Foraging patch selection may shift during the wet season, when vegetation cover and prey abundance and activity increase (Thiollay 1978), but dry conditions prevail during 8 months of the year, suggesting that our results are representative for most of the year when resources are limited. Although we did not measure prey densities, patch-level selection for a well-developed ground vegetation layer in transformed habitats appears to have been primarily related to optimisation of prey abundance, or quality, within foraging patches; for example, shrubs and a welldeveloped grass layer provide important shelter, foraging, and thermal regulation sites for lizards and rodents (Díaz 1992, Vasquez et al. 2002, Castellano and Valone 2006). In heavily grazed areas, patches of shrubs and grasses may become especially important refuges for terrestrial prey, which may explain their importance to foraging Dark-chanting Goshawks. Similarly, Dark-chanting Goshawks may have selected sorghum and millet fields for the comparatively high abundance of rodents associated with them (Buij et al. 2012).

Our results suggest that the persistence of Dark-chanting Goshawk populations in agroecosystems is based on a trade-off between prey quality and prey capture rates, governed by anthropogenic activities such as livestock grazing and tree clearance. Goshawks may only be able to persist where profitable, exploitable foraging patches are sufficiently common, or where it is possible to increase territory size to meet nutritional demands (Newton 1979, Kenward 1982). We found that Dark-chanting Goshawks required larger ranges to meet their food requirements in transformed habitats, where foraging patches were more widely spaced compared to natural habitats, despite the positive effect that some habitat modifications may have had for foraging. Our results further suggest that a moderate degree of human land-use, with livestock grazing reducing sward length, an increase in cultivation of food crops, openness, and shrubs, and the often selective preservation of tall trees, might be beneficial by maintaining or positively affecting prey accessibility and availability. Dark-chanting Goshawks are likely to decline, however, in areas where extensive vegetation clearance reduces the capacity of the habitat to support prey populations, or their exploitability. Such vegetation denudation is a continuing process in West Africa, which is likely to have contributed to the sharp decline of Dark-chanting Goshawks during the past four decades, as well as other sedentary raptors with comparable morphological traits and foraging ecology (Thiollay and Clobert 1990, Thiollay 2006). Additional pressure from increased human disturbance at nest sites and direct or indirect effects of pesticide use in croplands may further impact on raptor populations (Buij et al. 2013a). Future examinations are required to confirm this and to determine whether the observed differences in prey quality and range size negatively affect nestling condition, survival, and long-term reproductive output (Rodríguez et al. 2006, Buij et al. 2013b).

Management implications emanating from this study would be to conserve tall trees, pasture and shrubs in cultivated landscapes, thus maintaining adequate food and shelter for terrestrial prey animals exploited by Dark-chanting Goshawks. Unfortunately, land saturation and a general 
lack of financial means to enable sustainable cropping systems lead to heavily exploited agroecosystems increasingly deprived of natural vegetation cover (Lambin et al. 2003, Gray 2005). Appropriate agricultural intensification-related policy initiatives (Buij et al. 2013a), encouraged and enforced by state and traditional authorities, including silvicultural practices with designated pastures protected from heavy exploitation, might represent the only alternative to the progressive impoverishment of West Africa's savannas. Such action may help curb the gradual disappearance of sedentary Afrotropical raptors in the agro-ecosystems that increasingly dominate their distribution range.

\section{Supplementary Materials}

The supplementary materials for this article can be found at journals.cambridge.org/bci

\section{Acknowledgements}

This study was financially and logistically supported by the Institute of Environmental Sciences of the University of Leiden, and the Centre for Ecological and Evolutionary Studies, University of Groningen, the Netherlands. M. Bechard, M. Murphy, R. Limiñana, H. H. de Iongh, G. de Snoo, and two anonymous reviewers provided useful comments on a draft. G. Malan, S. Thomsett, A. Kemp, R. G. Bijlsma, M. Hammers, W. S. Clarke, and M. Virani provided valuable suggestions. H. Hamadou is thanked for his assistance with logistics.

\section{References}

Allen, M. E. (1989) Nutritional aspects of insectivory. PhD thesis. Michigan State University, USA.

Amo, L., Lopez, P. and Martin, J. (2007) Habitat deterioration affects body condition of lizards: A behavioral approach with Iberolacerta cyreni lizards inhabiting ski resorts. Biol. Cons. 135: 77-85.

Bamford, A. J., Monadjem, A. and Hardy, I. C. W. (2009) Nesting habitat preference of the African White-backed Vulture Gyps africanus and the effects of anthropogenic disturbance. Ibis 151: 51-62.

Barton, K. (2009). MuMIn: Multi-model inference. R Package Version 1.9.5. <http:// RForge.R-project.org/projects/mumin/>.

Beier, P. and Drennan, J. E. (1997) Forest structure and prey abundance in foraging areas of Northern Goshawks. Ecol. Appl. 7: 564-571.

Blaum, N., Rossmanith, E., Schwager, M. and Jeltsch, F. (2007) Responses of mammalian carnivores to land-use in arid savanna rangelands. Basic Appl. Ecol. 8: 552-564.

Bloom, P. H., Clark, W. S. and Kidd, J. W. (2007) Capture techniques. In D. Bird and K. Bildstein, eds. Raptor research and management techniques. Blaine, WA, USA: Hancock House Publishers.
Brink, A. and Eva, H. D. (2009) Monitoring 25 years of land cover change dynamics in Africa: A sample based remote sensing approach. Appl. Geogr. 29: 501-512.

Buij, R., Croes, B. M. and Komdeur, J. (2013a) The role of breeding range, diet, mobility and body size in associations of raptor communities and land-use in a West African savanna. Biol. Cons. 166: 231-246.

Buij, R., Folkertsma, I., Kortekaas, K., Iongh, De, H. H. and Komdeur, J. (2013 b) Effects of landuse change and rainfall in Sudano-Sahelian West Africa on the diet and nestling growth rates of an avian predator. Ibis 155: 89-101.

Buij, R., Kortekaas, K., Van Krimpen, R. R. D., Van Wijk, R., Van Der Zanden, S., Iongh, De, H. H., Heitkönig, I. M. A., Snoo, De, G. R. and Komdeur, J. (2013 C) Breeding performance of Grasshopper Buzzards in a natural and human-modified West African savanna. Condor 115: 47-57.

Buij, R., Van der Goes, D., Iongh, De, H. H., Gagare, S., Haccou, P., Komdeur, J. and De Snoo, G. R. (2012) Interspecific and intraspecific differences in habitat use and their conservation implications for Palaearctic harriers on Sahelian wintering grounds. Ibis 154: 96-110. 
Burnham, K. P. and Anderson, D. R. (2002) Model selection and multimodel inference: A practical information-theoretic approach. New York: Springer-Verlag.

Cardador, L., Planas, E., Varea, A. and Mañosa, S. (2012) Feeding behaviour and diet composition of Marsh Harriers Circus aeruginosus in agricultural landscapes. Bird Study 59: 228-235.

Castellano, M. J. and Valone, T. J. (2006) Effects of livestock removal and perennial grass recovery on the lizards of a desertified arid grassland. J. Arid Envir. 66: 87-95.

Chape, S., Harrison, J., Spalding, M. and Lysenko, I. (2005) Measuring the extent and effectiveness of protected areas as an indicator of meeting global biodiversity targets. Phil. Trans. Royal Soc. B 360: 443-455.

Clerici, N., Bodini, A., Eva, H. D., Gregoire, J-M., Dulieu, D. and Paolini, C. (2006) Increased isolation of two biosphere reserves and surrounding protected areas (WAP ecological complex, West Africa). J. Nature Cons. 15: 26-40.

Cooper, W. E., Jr and Whiting, M. J. (200o) Ambush and active foraging modes both occur in the scincid genus Mabuya. Copeia 1: $112-118$.

Díaz, J. A. (1992) Choice of compass directions around shrub patches by the heliothermic lizard Psammodromus algirus. Herpetology 48: 293-300.

Esri (1999) ArcView GIS. [Online.] Available at www.Esri.com.

Gessaman, J. A. (1987) Energetics. In B. A. Giron Pendleton, B. A. Millsap, K. W. Cline and D. M. Bird, eds. Raptor management techniques manual. Washington DC: National Wildlife Federation (Scientific and Technical Series).

Gray, L. C. (2005) What kind of intensification? Agricultural practice, soil fertility and socioeconomic differentiation in rural Burkina Faso. Geogr. J. 171: 70-82.

Harris, S., Cresswell, W. J., Forde, P. G., Trewhella, W. J., Woollard, T. and Wray, S. (1990) Home-range analysis using radiotracking data: a review of problems and techniques particularly as applied to the study of mammals. Mamm. Rev. 20: 97-123.

Herremans, M. and Herremans-Tonnoeyr, D. (2000) Land-use and conservation status of raptors in Botswana. Biol. Cons. 94: 3I-4I.

Holmes, C. W. (1974) The Massey grass meter. Dairy farming annual. Palmerston North: Massey University.

Johnson, D. H. (1980) The comparison of usage and availability measurements for evaluating resource preference. Ecol. 61: 65-71.

Kaufman, G. A. and Whitfield Gibbons, J. (1975) Weight-length relationships in thirteen species of snakes in the southeastern United States. Herpetology 31: 31-37.

Kenward, R. E. (1982) Goshawk hunting behaviour, and range size as a function of food and habitat availability. J. Anim. Ecol. 51: 69-80.

Kenward, R. E., Marcstrom, V. and Karlbom, M. (1981) Goshawk winter ecology in Swedish pheasant habitats. J. Wildl. Manage. 45: 397-408.

Lambin, E. F., Geist, H. J. and Lepers, E. (2003) Dynamics of land-use and land cover change in tropical regions. Ann. Rev. Env. Res. 28: 205-241.

Machange, R. W., Jenkins, A. R. and Navarro, R. A. (2005) Eagles as indicators of ecosystem health: is the distribution of Martial Eagle nests in the Karoo, South Africa, influenced by variations in land-use and rangeland quality? J. Arid Envir. 63: 223-243.

Marti, C. D., Bechard, M. J. and Jaksic, F. M. (2007) Food habits. In D. Bird and K. Bildstein, eds. Raptor research and management techniques. Blaine, WA, USA: Hancock House Publishers.

Marti, C. D., Steenhof, K., Kochert, M. N. and Marks, J. S. (1993) Community trophic structure: the roles of diet, body size, and activity time in vertebrate predators. Oikos 67: 6-19.

Masman, D., Gordijn, M., Daan, S. and Dijkstra, C. (1986) Bioenergetics of the kestrel, F. tinnunculus: The variability of natural intake rates. Ardea 74: 24-38.

Meik, J. M., Jeo, R. M., Mendelsson, J. R., III and Jenks, K. E. (2002) Effects of bush encroachment on an assemblage of diurnal lizard species in central Namibia. Biol. Cons. 106: 29-36.

Mosher, J. A. (1976) Raptor energetics: a review. Raptor Res. 10: 97-107. 
Nagy, K. A., Huey, R. B. and Bennett, A. F. (1984) Field energetics and foraging mode of Kalahari lacertid lizards. Ecology 65: 588-596.

Nelder, J. A. (1977) A reformulation of linear models. J. Royal Stat. Soc. 140: $48-77$.

Newton, I. (1979) Population ecology of raptors. Berkhamsted, UK: T. and A. D. Poyser.

Nishimura, K. (1991) Utilization of different prey type patches in the Ural Owl (Strix uralensis): a sit-and-wait predator. Behav. Ecol. 2: 99-105.

Nishimura, K. (1994) Decision making of a sit-and-wait forager in an uncertain environment: learning and memory load. $\mathrm{Am}$. Nat. 143: 656-676.

Oba, Y., Shintani, T., Nakamura, T., Ojika, M. and Inouye, S. (2008) Determination of the luciferin contents in luminous and nonluminous beetles. Biosc. Biotech. Biochem. 72: $1384-1387$

Ogada, D. L. and Kibuthu, P. M. (2009) Impacts of agriculture on the diet and productivity of Mackinder's Eagle Owls (Bubo capensis mackinderi) in Kenya. Biotropica 41:485-492.

Ouedraogo, I., Savadogo, P., Tigabu, M., Dayamba, S. D. and Odén, P. C. (2010) Systematic and random cover transitions in the tropical dry forest of Burkina Faso, West Africa. Int. J. Remote Sensing 32: 5229-5245.

Paré, S., Söderberg, U., Sandewall, M. and Ouadba, J. M. (2008) Land-use analysis from spatial and field data capture in southern Burkina Faso, West Africa. Agr. Ecosystems \& Env. 127: 277-285.

Rodríguez, C., Johst, K. and Bustamante, J. (2006) How do crop types influence breeding success in Lesser Kestrels through prey quality and availability? A modelling approach. J. Appl. Ecol. 43: 576-586.

Scholte, P. T. (2003) Immigration: a potential time bomb under the integration of conservation and development. AMBIO: J. Human Environ. 32: 58-64.

Secor, S. M. and Nagy, K.A. (1994) Bioenergetic Correlates of Foraging Mode for the Snakes Crotalus Cerastes and Masticophis flagellum. Ecology 75: 1600-1614.
Stephens, D. W. and Krebs, J. R. (1986) Foraging theory. Princeton: Princeton University Press.

Steyn, P. (1982) Birds of prey of southern Africa. Their identification and life histories. Cape Town, South Africa: David Philip.

Thiollay, J-M. (1978) Les migrations de rapaces en Afrique occidentale: adaptations écologiques aux fluctuations saisonnières de production des écosystèmes. Terre Vie 32: 89-133.

Thiollay, J-M. (2006) The decline of raptors in West Africa: long-term assessment and the role of protected areas. Ibis 148: 240-254.

Thiollay, J-M. (2007) Raptor declines in West Africa: comparisons between protected, buffer and cultivated areas. Oryx 41: 322-329.

Thiollay, J-M. and Clobert, J. (1990) Comparative foraging adaptations of small raptors in a dense African savanna. Ibis 132: 42-57.

UN World Population Prospects (2010) [Online.] Available at www.un.org/esa/population/

Vasquez, R. A., Ebensperger, L. A. and Bozinovic, F. (2002) The influence of habitat on travel speed, intermittent locomotion, and vigilance in a diurnal rodent. Behav. Ecol. 13: 182-187.

Virani, M. Z. and Harper, D. M. (2009) Factors influencing the breeding performance of the Augur Buzzard Buteo augur in southern Lake Naivasha, Rift Valley, Kenya. Ostrich 80: 9-17.

Walls, S. S. and Kenward, R. E. (2007) Spatial tracking. Radio tracking. In D. Bird and K. Bildstein, eds. Raptor research and management techniques. Blaine, WA, USA: Hancock House Publishers.

Ward, J. P., Jr, Gutiérrez, R. J. and Noon, B. R. (1998) Habitat selection by Northern Spotted Owls: the consequences of prey selection and distribution. Condor 100: 79-92.

Wasiolka, B., Blaum, N., Jeltsch, F. and Henschel, J. (2009) Behavioural responses of the lizard Pedioplanis 1. lineoocellata to overgrazing. Acta Oecol. 35: 157-162.

Williams, J. B., Anderson, M. D. and Richardson, P. R. K. (1997) Seasonal differences in field metabolism, water requirements, and foraging behavior of free-living aardwolves. Ecology 78: 2588-2602. 
RALPH BUIj ${ }^{1,2 *}$, HENRIËTTE F. SALOMONS 2,3 , JAN KOMDEUR ${ }^{2}$, MAURINE W. DIETZ ${ }^{3}$

${ }^{1}$ Animal Ecology, Alterra Wageningen UR, PO Box 47, 6700 AA Wageningen, Netherlands.

${ }^{2}$ Behavioural Ecology and Self-organization, Centre for Ecological and Evolutionary Studies, University of Groningen, Centre for Life Sciences, Nijenborgh 7, 9747 AG Groningen, Netherlands.

3 Animal Ecology Group, Centre for Ecological and Evolutionary Studies, University of Groningen, Centre for Life Sciences, Nijenborgh 7, 9747 AG Groningen, Netherlands.

\section{NIKIE VAN DORST}

Resource Ecology Group, Wageningen University, Droevendaalsesteeg za, 6708 PB Wageningen, Netherlands.

\section{BARBARA M. CROES}

Institute of Environmental Sciences, Leiden University, Einsteinweg 2, 2300 RA Leiden, Netherlands.

*Author for correspondence; email: ralph.buij@gmail.com

Received 23 August 2013; revision accepted 25 April 2014; Published online II December 2014 